\title{
Ruy Barbosa Nogueira, Tributarista do Ano.
}

\section{A Redação}

Em sessão realizada no salão nobre desta Faculdade, a 29 de setembro de 1977, a Mapa Fiscal Editora S.A. outorga, pela primeira vez, o prêmio Tributarista do Ano ao Dr. Ruy Barbosa Nogueira, Catedrático de Direito Tributário e Diretor da Faculdade de Direito da USP.

Com a presença dos familiares do homenageado, colegas da Congregação, amigos e alunos, além de representantes e membros do Poder Legislativo, Executivo e Judiciário, Juristas, Tributaristas de São Paulo e do Brasil, Professores das Universidades do Rio de Janeiro e Minas, e de outras altas personalidades do mundo político e jurídico, abre a solenidade, na presidência da mesa, Dr. Jairo Gonçalves, diretor da Mapa Fiscal Editora S.A. que, inicialmente, esclarece os motivos da criação do prêmio.

Diz, então, que o Prêmio Tributarista do ano fora instituído pelo Conselho Editorial e Mapa Fiscal Editora S.A., considerando a importância do Direito Tributário no aprimoramento dos mecanismos econômicos responsáveis pelo progresso social, quando ajustados à realidade fiscal, ao Direito e à Justiça.

Considerando, também, que os estudos tributários, ou a contribuição ao Direito Tributário merece mais que o prêmio o reconhecimento público, estabeleceu a eleição direta em todo o colegiado brasileiro, formado de advogados, agentes fiscais e contabilistas credenciados, que desempenham funções diretamente ligadas à tributação. A eleição realizou-se de janeiro a junho e por $61 \%$ dos votos totais foi escolhido o Professor Doutor Ruy Barbosa Nogueira.

\section{O Tributarista.}

O Professor Dr. Ruy Barbosa Nogueira bacharelou-se em Ciências Jurídicas e Sociais pela Faculdade de Direito da 
USP em 1945. Ainda estudante já se dedicava ao Direito Tributário tendo iniciado naquela época a extensa bibliografia especializada que, hoje, é literatura clássica. Estudou várias línguas, francês, inglês, italiano, espanhol e alemão, que lhe facilitaram, mais tarde, a pesquisa internacional do assunto e a exposição da matéria nas aulas e conferências proferidas em Universidades de vários países, como da Alemanha, em Munique, Heidelberg, Colônia e Bochum e nos Estados Unidos na Faculdade de Direito da Universidade de Columbia. Nesta Universidade, lecionou sobre a Reforma Constitucional Tributária, Incentivos Fiscais e Codificação Tributária do Brasil. Inaugurou, ainda, em Moçambique o primeiro Curso de Direito Fiscal.

Ruy Barbosa Nogueira estudou e escreveu sempre, provando invulgar dinamismo e capacidade de trabalho.

Muito jovem, recém formado, fez cursos regulares e especiais com o Professor Paul Durand da Faculdade de Direito de Paris e com ENRICo TUllio Liebman, da Faculdade de Direito de Milão; foi aluno e companheiro de escritório do Professor TUllio AsCARELli catedrático de Bolonha e Roma; fez curso de Informática Jurídica com o Professor MáRIo Losano, das Universidades de Turim e Milão; foi aluno de Pontes de Miranda e advogou com Francisco Campos. Com HEINRICH REINACH fundador da revista "steuer und Wirtschaft" e Pereira DE Almeida, fundou e publicou a primeira Coletânea, no Brasil, pelo sistema de folhas substituíveis, de legislação e jurisprudência Fiscal e Trabalhista (LIFT) ; com TITo REZENDE fundou e editou a Revista Fiscal de São Paulo.

Todas as atividades do tributarista premiado convergiram, pois, para o Direito Tributário, desde os bancos acadêmicos até o profícuo magistério da disciplina, que iniciou, em 1954, na Faculdade de Direito da Pontifícia Universidade Católica. Substituindo, então, o Professor Carval ho Pinto e o Professor FrEderico Marques, na regência da cátedra de Ciência das Finanças, criou o primeiro curso curricular de Direito Tributário, e regeu a Cadeira durante quatorze anos; desde 1963 é professor da Faculdade de Direito da USP. Primeiro, como Livre Docente de Direito Tributário e desde 1965 como Catedrático de Direito Tributário, por concurso de provas e títulos. Atualmente rege as disciplinas Direito Tributário, no ciclo profissionalizante, Direito Tributário Aplicado no ciclo de especialização e Direito Tributário Comparado no curso de mestrado e doutorado. 
Em 1974, integrando a lista tríplice apresentada ao Reitor da USP, foi indicado e tomou posse do cargo de Diretor da Faculdade de Direito por quatro anos.

Como professor universitário e Diretor da Faculdade de Direito da Universidade de São Paulo idealizou e fundou o Instituto Brasileiro de Direito Tributário, reconhecido como entidade complementar à USP, e conta com mais de 600 tributaristas do Brasil e do Exterior.

$\mathrm{Na}$ presidência do mesmo Instituto, desde sua instalação, criou a Mesa de Debates realizando mais de 200 reuniões semanais e promovendo cursos anuais de extensão universitária, para graduados e graduandos de várias universidades. Dentre inúmeros destes cursos promovidos como serviço à comunidade, em 1977, já concluiu, no salão nobre desta Faculdade, o $20^{\circ}$ Curso Sesquicentenário com centenas de matriculados de vários Estados.

Além das atividades docentes, o primeiro "Tributarista do Ano" exerceu, concomitantemente, inúmeras outras atividades de caráter profissional, administrativo e político. Foi advogado chefe da Federação das Indústrias do Estado de São Paulo, Juiz do Tribunal de Impostos e Taxas do Estado e Secretário de Estado dos Negócios Jurídicos de São Paulo, e é presidente da Comissão de Legislação e Recursos do Conselho Universitário da USP. Participa ativamente de várias Associações de Classe, tanto nacionais como internacionais. Desde 1945 é membro da International Fiscal Association, com sede em Haia. E sócio fundador da Associação Brasileira de Direito Financeiro, com sede no Rio de Janeiro e desde 1949 é membro do Instituto dos Advogados de São Paulo. É titular da Academia Paulista de Direito. Membro efetivo da Permanent Law Comittee of Inter-American Bar Association, com sede em Washington e membro do Instituto Latino-Americano de Derecho Tributário e da Associação Paraguaia de Derecho Administrativo e Tributário.

\section{Referência Bibliográfica}

O Professor Dr. RUY BARBosa NogUeira produziu extensa bibliografia especializada que conta mais de 400 trabalhos, abrangendo as publicações do tempo acadêmico.

Desde 1948, tem publicado obras destinadas a auxiliar o estudo da disciplina nos cursos de especializa- 
ção e pós-graduação, como $O$ Direito Tributário Comparado edição Saraiva, SP 1971, traduzido a Convite da Organização dos Estados Americanos a comparação dos códigos dos países da ALALC, o ensaio de uma bibliografia para auxiliar pesquisas de Direito Tributário Comparado em Português, Espanhol, Italiano, Francês, Inglês e Alemão. Publicou também, de 1969 a 1973, e sobretudo em 1971, como coletâneas, estudos selecionados de casos e problemas tributários, feitos pelos alunos, no total de 1.884 páginas, sob sua direção e com sua colaboração, que constituíram incentivo à produção discente, sob o título: Direito Tributário, edição Bushatsky.

Em 1974, também sob sua direção e colaboração, foi publicada a obra Estudos Tributários, com 513 páginas, em homenagem à memória de RUBENS GOMES DE SOUSA, Edição Resenha Tributária.

Em 1975, publicou Teoria e Prática do Direito Tributário, em colaboração com seu filho, Professor PaUlo RoBERTo CABRAL NogueIRA -, edição da Editora Resenha Tributária. Ainda em 1975, foram publicados, sob sua direção, os Debates Tributários, edição do Instituto Brasileiro de Direito Tributário.

Direito Tributário Aplicado em colaboração com seu filho Paulo Roberto Cabral Nogueira foi outra obra publicada para os alunos do ciclo de especialização, em 1976, com 471 páginas, pela Editora da Universidade de São Paulo. Nesse mesmo ano de 1976, reescreveu e publicou em $4 .^{a}$ edição o Curso de Direito Tributário indicado não só em muitas Faculdades de Direito do Brasil como do Exterior.

Neste ano de 1977, com a colaboração do professor PAULo ROBERTo CABRAL NoGUEIRA, publica em dois volumes, pela Editora Forense, o Direito Tributário Aplicado e Comparado, dedicado aos alunos do $5 .^{\circ}$ ano (Direito Aplicado) e aos pósgraduandos da área de Direito Tributário Comparado; e está publicando, com colegas do IBDT, a tradução do famoso Código Tributário da República Federal da Alemanha, recentemente promulgado naquele país, após 12 anos de estudos e reformulações do Parlamento Federal Alemão, a Abgabenordnung.

As obras aqui referidas foram as últimas publicações do professor laureado e demonstraram sua constante preocupação em transmitir ensinamento teórico e prático atualizado da matéria. 


\section{A Entrega do Prêmio e a Saudação de Miguel Reale.}

Saúda o Tributarista do Ano, em nome da Congregação de Professores da Faculdade de Direito da USP, o Professor Dr. Miguel Reale, catedrático de Filosofia do Direito, e decano da mesma Faculdade, após fazer-lhe a entrega solene do prêmio, que constou de um diploma pergaminhado e medalha, onde se registraram as razões da outorga.

Diz o orador sentir-se premiado, também, porque a láurea de um aluno estende-se a seu professor e à Faculdade, pois o "sentido de comunicação e de comunhão" marca o processo histórico da Faculdade de Direito da Universidade de São Paulo.

Referindo-se à personalidade do homenageado, exalta-lhe duas características importantes, i.e., de natureza cultural e ética. Quanto à primeira, o Professor Dr. Ruy Barbosa Nogueira contribuiu, através de pesquisa constante e estudos acurados, para se estabelecerem as bases dogmáticas, os pressupostos teóricos e doutrinários do Direito Tributário Nacional, que o tornam um ramo autônomo do Direito.

Quanto à segunda, ao aspecto moral, refere-se ao amor que o laureado dedica ao Direito Tributário, transformando-o em razão de sua existência e envolvendo-o na participação dos homens e do Direito.

Publica-se a seguir o discurso de saudação do Professor Dr. Miguel Reale, tomado por gravação e revisto pelo autor.

\section{Discurso de Miguel Reale.}

Sinto-me, esta manhã, muito mais do que o orador que saúda a quem recebe um prêmio, meu caríssimo amigo RUY BARbosa NogueIRA. Sinto-me também como premiado. É que, quando um ex-aluno recebe uma láurea, ela se estende imediatamente à pessoa de seu Professor. Vim, hoje, para corresponder à gentileza do convite recebido na dupla qualidade de professor mais antigo da Faculdade de Direito da Universidade de São Paulo, como decano de nossa Congregação, e como ex-professor de Filosofia do Direito daquele que com tanta justiça recebe o prêmio de Tributarista do ano de 1976.

RUY BARBosa Nogueira, o ilustre Mestre e Diretor da Faculdade de Direito de São Paulo, tem todos os títulos para fazer jus ao reconhecimento público de seu trabalho. 
O que desejo acima de tudo acentuar, na atividade desenvolvida pelo Professor RUY BARBosa NogUEIRA, são duas notas que o singularizam: uma de natureza cultural; outra de natureza ética.

A característica de natureza intelectual diz respeito à atitude que o Mestre paulista soube assumir perante o Direito Tributário. Todos nós sabemos que o Direito Tributário é uma das disciplinas mais recentes no campo das ciências jurídicas. Lembro-me de que, quando ingressei nesta casa, o Direito Tributário não era senão um apêndice do estudo de Economia Política - "Economia Política e Noções de Ciência das Finanças". Nem sequer, portanto, o Direito Tributário era um apêndice autônomo, mas simples adendo, uma parte que integrava a Ciência das Finanças, de maneira secundária.

Pode dizer-se que era assim, não apenas no Brasil mas em quase todo mundo. O Direito Tributário ainda não havia assumido aquelas características que hoje o exornam, de uma disciplina jurídica altamente estruturada, com seu objeto próprio bem definido, e com o seu processo de pesquisa claramente situado no âmbito da Jurisprudência.

Não é preciso ser tão antigo para se fazer essa observação. $\mathrm{Na}$ realidade, num lapso de quarenta anos, operou-se transformação profunda no campo que está sendo objeto deste curso, conduzido com tanto brilho e tanto êxito.

Qual a razão dessa mudança extraordinária?

A razão da alteração operada na imagem mesma do Estado.

Já não há mais que falar no Estado, absenteista, distante e separado das contingências humanas, das atividades sociais e culturais. O Estado, em nossos dias, ao contrário, até mesmo nos atemoriza pela sua contínua interferência em todos os setores da atividade social. O Estado cresceu de tal forma que já nos preocupa, no sentido de que estamos começando a pensar no vaticínio do grande filósofo NIETZCHE, sobre o monstro frio que iria devorar os homens e as coletividades. Mas, deixando de lado esse aspecto negativo e pessimista, é inegável que o Estado cresceu porque se mudou também o conceito do Direito. Não mais o Direito formal, das simples "declarações" que ficavam no papel, mas do Direito como substância viva, adquirindo dimensões da vida humana. O Estado de Direito converte-se em Estado da Justiça Social. O Estado, em lugar de ser apenas testemunha ou guardião do processo social, é propulsor por excelência desse processo. Passa a ser partícipe 
direto da experiência humana. O Estado empresário atua nessa veste, planejando e programando como se fora uma entidade empresária.

Temos, assim, o Estado atuante e presente, que reclama cada vez maiores recursos para atender à sua programação social, sem falar nos crescentes investimentos de ordem militar. Vemos, pois, que a atuação do Estado legitima as imposições feitas aos indivíduos para formação da receita pública, mas há que estabelecer limites e impedir abusos. É por essa razão que dois aspectos foram se distinguindo. A Ciência das Finanças viu crescer dentro dela, para se desprender, como uma criança se despreende do ventre materno, uma disciplina nova que é o Direito Tributário. Quais a posição e a dimensão do indivíduo dentro deste macrocosmo que é a figura estatal? O Direito Tributário constitui, por certo, a disciplina de contrapartida econômica que o Estado exige dos membros da comunidade, mas representa muito mais a dimensão do indivíduo perante o Fisco, a salvaguarda dos valores individuais e dos direitos fundamentais do homem perante o poderio estatal.

Ora, se uma disciplina jurídica surge com tanta responsabilidade, no que diz respeito à defesa do homem e da sua autonomia do ponto de vista econômico, ela exige rigorosas pesquisas do ponto de vista doutrinário e dogmático.

Peço a vossa atenção sobretudo sobre esse aspecto da obra do Prof. RuY Barbosa NogueIra. O que mais me sensibiliza em suas contribuições é o seu embasamento teórico e doutrinário. Ele poderia ter-se contentado, como fazem vários tributaristas, com o aspecto da aplicação legislativa. Mas, enquanto o jurista fica adstrito à aplicação das normas, ele está traind.o, de certo modo, a si mesmo, bem como faltando às responsabilidades que tem para com a Ciência e para com a Justiça.

O Direito não se resolve em simples interpretação da lei, nem em mera aplicação passiva de regulamentos, visto representar a inserção do diploma legislativo num contexto teórico e ético que dá vida e espiritualidade aos textos normativos. É só então que se desenvolve o trabalho dogmático ou científico do Direito. Pois, bem, o que singulariza a obra do Prof. RuY BARBosa Nogueira é o fato de estar contribuindo, mais do que qualquer outro, para estabelecer as bases dogmáticas, os pressupostos teóricos e doutrinários do Direito Tributário Nacional. Essa construção teórico-dogmática do Direito Tribu- 
tário era fundamental para que esse ramo da jurisprudência adquirisse autonomia científica, categoria e dignidade própria no mundo da Ciência Jurídica. Enquanto um campo de estudo não elabora a sua própria dogmática, não é mais que um ramo da legislação, sem ter adquirido ainda a autonomia que brota da ciência e da consciência científica. É este o primeiro aspecto a que desejava dar realce, pois, através de obras fundamentais, a começar de seu precioso Curso de Direito Tributário e das valiosas monografias que se sucederam, tivemos a prova cabal de um professor que não deixa passar um dia, sem lhe dedicar uma linha, a atenção de um escrito revelador em seu empenho teórico-prático.

A bibliografia vastíssima de RUY BARBosA NoGUEIRA por si só demonstra outra característica de seu espírito que é a compreensão prática da ciência jurídica. Quem vos fala, como filósofo do Direito, poderia, aparentemente, só dar valor aos elementos teóricos, mas essa é uma visão unilateral e falha das preocupações filosóficas. O verdadeiro filósofo do Direito desconfia dos esquemas teóricos desprovidos de qualquer destinação ou efeito prático, visto ser, próprio do Direito a sua realizabilidade.

Anda bem, por conseguinte, o Prof. RUY BARBosa NoGUEIRA quando investiga os aspectos teóricos do Direito Tributário sem olvidar as implicações de natureza prática indispensáveis ao mundo jurídico.

Compreendo que estas palavras interessam fundamentalmente àqueles que vivem no mundo do Direito. Sei que minhas asserções interessam sobretudo àqueles que fazem do Direito uma experiência de todas as horas e de todos os dias. Bem sei que as minhas palavras interessam especialmente àqueles que compreendem que no Direito está um sinal da dignidade humana. Trabalhando, em suma, para a Dogmática Jurídica e para a Ciência do Direito, RUY BARBosa NoGUEIRA está trabalhando para a perfectibilidade mesma da criatura humana.

É aqui que surge a outra dimensão da personalidade que hoje estamos homenageando. É o aspecto de dedicação moral. RUY BARbosa NogueIRA não se dedica à Ciência do Direito e ao Direito Tributário de maneira complementar, nem tampouco como homem que friamente assume uma tarefa de natureza cultural. Ele ama o Direito e o Direito Tributário. Transforma o Direito Tributário em razão de sua existência e de sua participação social. 
O que me entusiasma na atuação de RUY BARBosa NoGUEIRA é o seu contínuo contacto com a mocidade e com os seus colegas. As suas iniciativas múltiplas no sentido de que - Direito Tributário não fique confinado e restrito a uma minoria, mas se converta em patrimônio comum dos homens e do Direito, dos bacharéis em geral.

Compreende-se que um mestre, com essa vocação ética, dedique especial atenção aos problemas do estudante, realizando uma obra de comunicação social dentro desta Faculdade que reputo inédita por parte de um Diretor.

O que Vossa Excelência, professor RUY BARBosa NoGUEIRA tem feito, indo ao encontro do estudante e trazendo-o para a convivência direta da Diretoria da Faculdade, é uma obra que o enobrece, mostrando que não é apenas o professor que nós aqui estamos homenageando, esta manhã, mas o homem, com as suas características fundamentais, os seus valores afetivos, entre os quais o da cordial compreensão humana.

Como seu colega e seu antigo Mestre, quero neste momento, abusando deste instante, dizer-lhe, caríssimo amigo RUY BARBosa NogUEIRA, que este prêmio é seu, mas é também da Faculdade de Direito. Este prêmio também é nosso, porquanto o sentido de comunicação e de comunhão é que marca e distingue para todo o sempre o processo histórico da Faculdade de Direito de São Paulo.

\section{Ruy Barbosa Nogueira Agradece o Prêmio e Profere a Aula de Encerramento do Curso "Direito Tributário Aplicado e Comparado".}

Após a saudação de Miguel Reale, o homenageado toma a palavra para agradecer o prêmio recebido, e estende seus méritos aos familiares, professores e amigos. Diz ser "fortuna do destino" continuar sendo aluno de Miguel Reale e agradece à Faculdade e à Congregação a acolhida que lhe deram desde o pré-jurídico. Relembrou, a seguir, o tempo acadêmico e cada um dos professores, inclusive Heinrich Reinach, seu primeiro professor de alemão e de direito germânico.

Através de Reinach relacionou-se com autores, magistrados e professores alemães, o que lhe permitiu estudar na Alemanha em várias ocasiões e, onde, mais tarde, proferiu conferências e aulas em diversas Universidades. Finalmente, agradece mais uma vez a todos que contribuíram para sua formação jurídico- 
tributária e para a "consciência do dever de transmiti-la", que lhe grangearam a outorga do prêmio.

Após a dedicatória do prêmio, o Professor Dr. Ruy Barbosa Nogueira profere a aula de encerramento do Curso de Direito Tributário Aplicado e Comparado, que se constituiu em preciosa condensação de vários temas da matéria, desde seu histórico, fundamentos filosóficos, objeto, até a autonomia e aplicação nos sistemas brasileiro e estrangeiros. Fala ainda sobre a importância do Direito Tributário nas relações econômicas internacionais e, finalmente, a respeito do ensino universitário da disciplina, imprescindível para a formação do advogado, na sociedade atual.

Por seu caráter eminentemente doutrinário, publica-se a aula na secção de Doutrina deste fascículo.

\section{Palavras de agradecimento de Ruy Barbosa Nogueira.}

Quem desde os bancos do ensino secundário vem trabalhando no campo tributário, ingressa nesta Faculdade, torna-se advogado, professor da matéria, passa a escrever livros e vem lecionando Direito Tributário há 23 anos, e ainda, com a ajuda de centenas de estudiosos consegue fundar um Instituto e promover cursos com centenas de alunos como este, não pode deixar de estar emocionado e muito feliz, precisamente nesta Faculdade, entre seus familiares, companheiros, alunos e seus próprios professores, quando, juntamente com todos esses amigos, recebe o título de tributarista do ano.

Quero agradecer aos eleitores, ao Conselho Editorial e à Direção do Mapa Fiscal Editores, que concretizaram no Brasil esta eleição, mas receber este título em nome de minha esposa e filhos, de meus professores, meus companheiros do Instituto, ex-alunos e atuais, pois a todos eles é que devo a formação do grupo de estudos.

Agradeço a oração do meu querido e grande Mestre Miguel Reale, jusfilósofo, Mestre de Escola, fundador do Instituto Brasileiro de Filosofia e que por seu ensino, por suas obras e pelo modelo de pensador, professor, jurista, numa palavra, humanista, tem a capacidade de irradiação de cultura e o dom da bondade. A ele não posso agradecer com palavras, mas com o coração, admiração e gratidão. Ter sido aluno do Professor Miguel ReAle é um privilégio, mas ter a ventura de continuar sendo, consideramos fortuna do destino.

Agradecendo ainda a esta Faculdade que nos abrigou desde os bancos do curso pré-jurídico e à sua Douta Congregação 
que nos confiou a Diretoria desta grande Escola, queremos também agradecer a todos os amigos.

Permitam-me agora algumas homenagens e impressões do tempo de estudante.

Queremos iniciar um pouco antes da Faculdade e lembrar de um jurista de escol, que me guiou os primeiros passos no Direito. Tinha eu 16 anos quando ingressei nos serviços jurídicos da Federação das Indústrias e comecei na prática jurídica com TÁCITO DE AlmeIdA. filho do grande Mestre desta casa Professor Estêvão DE ALMEIDA. Ali pude sempre conjugar o trabalho e o estudo dentro de intensa e extensa casuística. Ingressando no colégio Universitário desta Faculdade em 1938, logo me impressionou o ensino de História da Filosofia de CASTRO NERY; dentre as muitas matérias era intensa a preparação em literatura universal e latim; no $1 .^{\circ}$ ano do bacharelado foi básico o ensino de Direito Romano do Professor ALEXANDRE CORRÊA; no $2 .^{\circ}$ não posso esquecer de Direito Constitucional com o germanista Professor GENÉSIo DE MOURA e muito especialmente as aulas de Ciência das Finanças do excelente didata Professor TheotônIo MonteIro DE BARRos; no Direito Comercial, que iria até o $4 .^{\circ}$ ano, o genial Tullio ASCARELLI; a partir do $3 .^{\circ}$ ano foi extraordinário o ensino de EnRico Tullio Liebman em processo; no $4 .^{\circ}$ devo destacar Direito Administrativo com MÁRIo MAZAGÃo e Direito do Trabalho com o Professor CESARINo JUNIOR; no $5 .^{\circ}$ ano foi sobretudo marcante o ensino de Filosofia do Direito do Professor Miguel REALE. Terminada a Faculdade continuamos com verdadeiro aprendizado teórico e prático no escritório, com o Professor AsCARELLI. A esse tempo não podemos esquecer de HEINRICH REINACH, irmão do jusfilósofo REINACH, grande especialista do Direito Tributário, que fora notável advogado junto à Suprema Corte Tributária da Alemanha e fundador de uma das mais importantes Revistas que até hoje existe naquele país (Imposto e Economia - Steuer und Wirtschaft), na qual tivera a colaboração de ENNO BECKER e de ALBERT HENSEL. REINACH foi nosso primeiro professor de alemão e de direito germânico. Foi ele que nos abriu as portas de Munique e o relacionamento com os autores, professores e magistrados e lá pudemos ir estudar várias vezes. Mais tarde pudemos ir a vários países, inclusive estudar métodos e dar conferências ou aulas, graças à bondade de grandes colegas tributaristas. 
A todos esses Mestres e Amigos que com bondade e doação nos ajudaram e com seus exemplos nos incutiram o dever de transmitir experiência, não só dedicamos a láurea de hoje, mas também a consciência desse mesmo dever que nos legaram.

Dentro, pois, deste contexto, peço licença a meus Mestres presentes para ministrar aos alunos a aula final deste curso. 